\title{
Endoscopic sleeve gastroplasty of the remnant stomach in Roux-en-Y gastric bypass: a novel approach to a gastrogastric fistula with weight regain
}

A gastrogastric fistula is a channel that develops between the gastric pouch and gastric remnant following a Roux-en-Y gastric bypass (RYGB). The management includes symptom control, high dose acid suppression, and consideration of closure techniques for those with persistent symptoms. While endoscopic approaches are less invasive than surgical repair, less than one-third of fistulas remain closed. Here, we demonstrate a novel approach whereby we performed endoscopic sleeve gastroplasty (ESG) of the remnant stomach through the gastrogastric fistula, followed by reduction in volume of the gastric pouch ( Video 1).

A 56-year-old man with a history of RYGB performed 13 years previously presented with weight regain of 100 pounds over 1 year. Index endoscopy showed a 3-cm gastrogastric fistula with an ulcerated and completely stenotic gastrojejunal anastomosis (- Fig. 1 a). We began the procedure by marking the estimated midline on the posterior surface of the stomach using argon plasma coagulation (APC), so we could ensure that stitches were placed only on the greater curvature

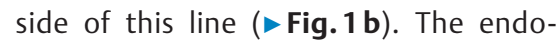
scopic suturing device was then advanced through the gastrogastric fistula. A series of six running stitches were placed in a triangular pattern (anterior, greater curvature, posterior configuration), and this was repeated five to seven times ( $>$ Fig. 1 c). This particular stitch pattern has the effect of longitudinally contracting the stomach to pull down the fundus, while moving from the antrum proximally ( $\mathbf{F i g . 1} \mathbf{d}$ ).

Following successful ESG, the volume of the gastric pouch is reduced, thereby shunting oral intake through the gastrogastric fistula and into the repaired remnant stomach. An upper gastrointestinal contrast study demonstrated that enteric contrast filled a small gastric pouch then opacified the remnant stomach fol-

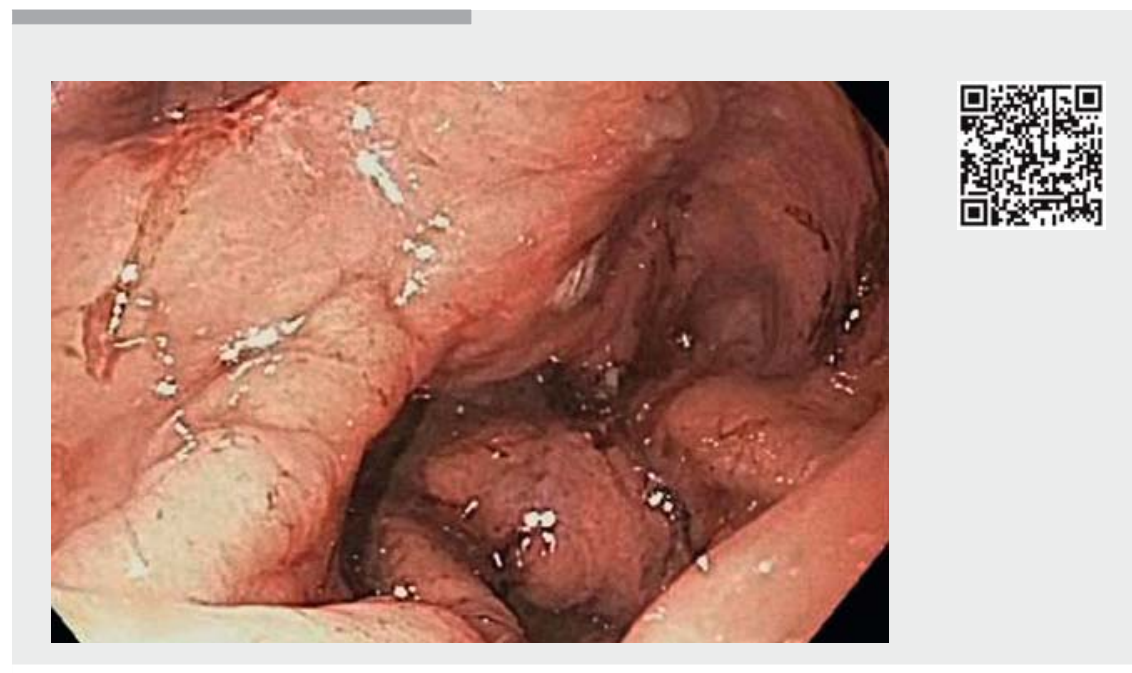

Video 1 Endoscopic sleeve gastroplasty of the remnant stomach following a Roux-en-Y gastric bypass as a treatment for gastrogastric fistula with weight regain.
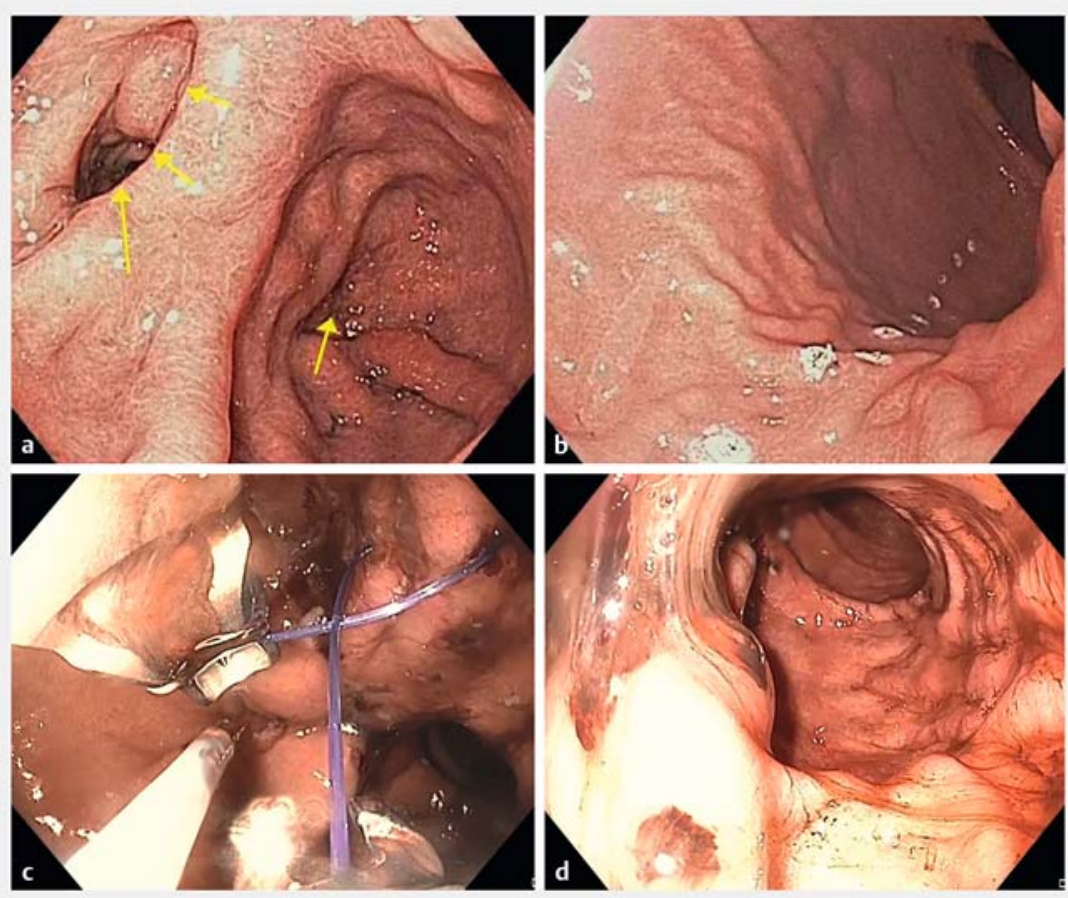

Fig. 1 Endoscopic images showing: a a gastrogastric fistula (three arrows) with an ulcerated and stenotic gastrojejunal anastomosis (single arrow); $\mathbf{b}$ the posterior surface of the remnant stomach, which has been marked by argon plasma coagulation; $\mathbf{c}$ endoscopic stitches placed in a triangular pattern; $\mathbf{d}$ the appearance following successful endoscopic sleeve gastroplasty of the remnant stomach. 


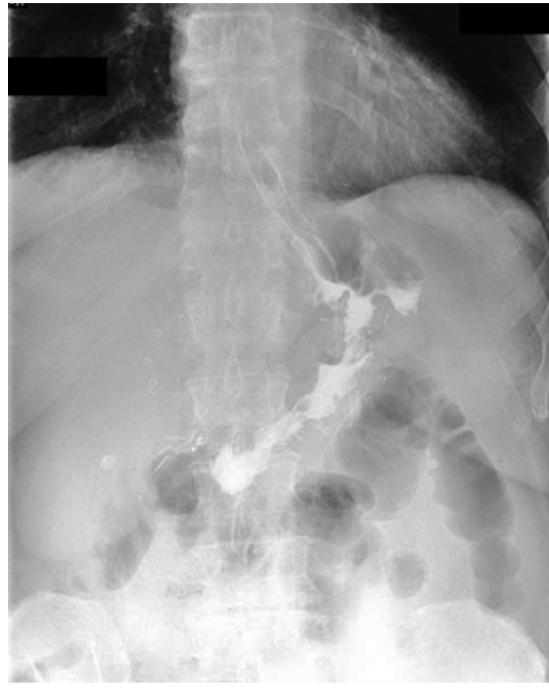

- Fig. 2 Image from an upper gastrointestinal contrast study showing enteric contrast filling a small gastric pouch then opacifying the remnant stomach followed by the duodenum, rather than passing through the gastrojejunostomy.

lowed by the duodenum, rather than passing through the gastrojejunostomy ( Fig. 2).

In conclusion, ESG of the gastric remnant through an existing gastrogastric fistula is a novel, technically feasible, and effective treatment for weight regain following RYGB.

Endoscopy_UCTN_Code_TTT_1AT_2AC

\section{Competing interests}

C. Thompson has acted as a consultant and received research support from Apollo Endosurgery, Inc. and Olympus; has been a consultant for Boston Scientific; and has been a consultant, and received royalties and stock from Covidien.

The authors

Allison R. Schulman ${ }^{1}$, Mustafa Huseini' ${ }^{1}$, Christopher C. Thompson ${ }^{1,2}$

1 Brigham and Women's Hospital, Boston, Massachusetts, USA

2 Harvard Medical School, Boston, Massachusetts, USA

\section{Corresponding author}

\section{Christopher Thompson, MD}

Division of Gastroenterology, Brigham and Women's Hospital, 75 Francis St. ASBII, Boston, Massachusetts 02115, USA

Fax: +1-617-264-6342

cthompson@hms.harvard.edu

\section{Bibliography}

DOI https://doi.org/10.1055/s-0044-101829

Published online: 22.3.2018

Endoscopy 2018; 50: E132-E133

(c) Georg Thieme Verlag KG

Stuttgart · New York

ISSN 0013-726X

\section{ENDOSCOPY E-VIDEOS}

https://eref.thieme.de/e-videos

口回 Endoscopy E-Videos is a free y access online section, reporting 靣: on interesting cases and new

techniques in gastroenterological endoscopy. All papers include a high quality video and all contributions are freely accessible online.

This section has its own submission website at

https://mc.manuscriptcentral.com/e-videos 